\title{
ANALISIS KEMAMPUAN BERPIKIR KRITIS SISWA MELALUI MODEL PEMBELAJARAN ADVANCE ORGANIZER PADA MATERI LARUTAN ELEKTROLIT DAN NONELEKTROLIT
}

\section{ANALYSIS OF STUDENT CRITICAL THINKING THROUGH LEARNING MODEL ADVANCE ORGANIZER ON MATERIAL ELECTROLYTE AND NONELECTROLYTE SOLUTIONS}

\author{
Siti Mastiah, Nurlaili*, Muflihah \\ Program Studi Sarjana Pendidikan Kimia, Fakultas Keguruan dan llmu Pendidikan, Universitas Mulawarman, \\ Samarinda, Kalimantan Timur, Indonesia \\ *Corresponding Author : nurlailisyamsul@yahoo.co.id
}

\begin{abstract}
ABSTRAK
Keterampilan berpikir kritis sangat diperlukan dalam memecahkan masalah-masalah dalam ilmu kimia yang berupa teori, konsep, hukum, dan fakta. Pelajaran kimia siswa tidak hanya mengembangkan pengetahuan, pemahaman dan kemampuan analisis tetapi juga perlu mengembangkan kemampuan berpikir kritis siswa. Penelitian ini bertujuan untuk mengetahui kemampuan berpikir kritis siswa pada materi larutan elektrolit'dan nonelektrolit dengan menggunakan model pembelajaran Advance Organizer. Sampel dalam penelitian ini adalah siswa kelas X Multimedia SMK Negeri 20 Samarinda yang berjumlah 30 orang. Teknik pengumpulan data dilakukan melalui soal materi larutan elektrolit dan nonelektrolit dengan menggunakan indikator berpikir kritis di setiap akhir pertemuan selama dua kali pertemuan. Menghitung skor dari jawaban siswa dan mengubah skor dalarn bentuk persentase sehingga dapat terlihat kemampuan berpikir kritis siswa. Hasil penelitian menunjukkan bahwa nilai kemampuan indikator interpretasi sebesar $72,13 \%$ dengan kategori cukup; indikator kemampuan menjelaskan sebesar 67,64\% dengan ketegori cukup; indikator inferensi sebesar $75,25 \%$ dengan kategori baik; indikator analisis sebesar 83,06\% dengan kategori baik; indikator evaluasi sebesar 83,67\% dengan kategori baik; dan indikator self regulation sebesar 68,75\%, dengan kategori cukup, adapun rata-rata hasil penelitian kemampuan berpikir kritis siswa SMK Negeri 20 Samarinda sebesar 75,08\% dongan kategori baik
\end{abstract}

Kata kunci : kemampuan berpikir kritis, larutan elektrolit dan nonelektrolit, advance organizer

\footnotetext{
ABSTRACT

Critical thinking skills are indispensable in solving problems in chemistry in the form of theories, concepts, laws, and facts. This led to the chemistry lesson students should not only develop the knowledge, understanding and analytical skills, but also need to develop students' critical thinking abilities. The use of ARIAS learning can increase the activity of students that will hone This study aims to determine students critical thinking abilities on the material and the electrolyte solution nonelectrolyte using Advance Organizer. The samples in this study were students of class X Multimedia SMKN 20 Samarinda totaling 30 people. Data was collected through problems using critical thinking indicators at the end of each meeting during the two meetings. Calculate the scores of the students 'answers and change the score in percentage form so it can be seen students' critical thinking skills. The results showed that the value of the indicator interpretation ability of $72,13 \%$ with enough categories; indicator describes the ability of $67,64 \%$ with enough categories; inference indicator amounted to $75,25 \%$ in both categories; analytical indicator of $83,06 \%$ with a good category; evaluation indicators of $83,67 \%$ with a good category; and indicators of self-regulation by $68,75 \%$ with enough categories, while the
} 
average of the results of students' critical thinking skills SMK 20 Samarinda at 75,08\% with both categories

\section{Keywords: critical thinking ability, electrolyte and nonelectrolyte solutions, advance organizer}

\section{PENDAHULUAN}

Pendidikan merupakan salah satu pengantar majunya suatu bangsa agar dapat meningkatkan kualitas. Meningkatnya kualitas pendidikan ditentukan oleh guru. Guru sebagai fasilitator seharusnya menciptakan suasana belajar yang menyenangkan dan kondusif sehingga tidak hanya terjadi transfer ilmu yang efektif melainkan juga mampu menggali semua potensi yang dimiliki siswa. Pelajaran kimia diharapkan tidak hanya memberikan pengetahuan sebanyak-banyaknya tetapi mampu berpikir kritis, kreatif serta bertanggung jawab terhadap peristiwa sehari-hari yang relevan. Pelajaran kimia di sekolah cenderung hanya memberikan informasi secara klasikal kepada siswa akan membuat siswa kurang termotivasi dalam mengikuti pelajaran. Model pembelajaran merupakan suatu pola yang digunakan sebagai pedoman dalam merencanakan pembelajaran di kelas atau pembelajaran dalam setting tutorial dan untuk menentukan perangkat-perangkat yang digunakan dalam pembelajaran (Trianto, 2007). Adapun model pembelajaran yang diharapkan dapat mengatasi masalah tersebut yaitu model pembelajaran advance organizer. Advance organizer merupakan suatu cara belajar untuk memproleh pengetahuan baru yang dikaitkan dengan pengetahuan yang telah ada pada pelajaran (Widiyowati, 2015)

Pemahaman siswa terhadap materi yang diajarkan terkadang sangat sulit dipahami dan diingat oleh karena itu perlu adanya strategi pembelajaran yang diaplikasikan kepada siswa sehingga dapat meningkatkan keaktifan, kreatifitas, pemahaman, serta berpikir kritis siswa. Berpikir kritis mampu mempengaruhi kehidupan seseorang. Hal itu disebabkan berpikir kritis akan membuat seseorang menjadi pengambil keputusan yang baik (Peter A., 2004). Keterampilan berpikir kritis sangat penting bagi siswa karena dengan keterampilan ini siswa mampu bersikap rasional dan memilih pilihan yang terbaik bagi dirinya. Berpikir kritis yang terdiri 6 indikator meliputi interpretasi, kemampuan menjelaskan, inferensi, analisis, evaluasi dan self regulation. Tujuan yang ingin dicapai penelitian ini adalah untuk mengetahui kemampuan berpikir kritis siswa terhadap penggunaan melalui advance organizer pada materi larutan elektrolit dan non elektrolit.

\section{METODE PENELITIAN}

Populasi penelitian ini seluruh siswa kelas $\mathrm{X}$ SMK Negeri 20 Samarinda. Pengambilan sampel berdasarkan teknik purposive sampling yang didasarkan pada pertimbangan yang dibuat peneliti (Notoatmodjo, 2010) sebanyak 30 siswa diajarkan dengan model advance organizer. Agar mencapai tujuan penelitian yang ditetapkan prosedur yang sistematis. Prosedur penelitian menjadi 3 tahap yaitu: tahap persiapan, tahap pelaksanaan dan tahap penyelesaian. Perangkat pembelajaran adalah RPP, LKS serta soal dengan indikator berpikir kritis menurut Facione. Adapun teknik pengumpulan data dalam penelitian ini adalah berupa tes (post test tiap akhir pertemuan) yang berisi enam indikator berpikir kritis dan non tes (lembar observasi).

Langkah-langkah untuk menganalisis data yaitu memberikan skor mentah untuk setiap jawaban siswa yang mengacu pada pedoman penilaian yang telah dibuat, menghitung nilai yang diperoleh siswa dari skor tes tertulis untuk masing-masing indikator kemampuan berpikir kritis setiap pertemuan, dengan menggunakan rumus yang dikemukakan oleh Arikunto, (2009), sebagai berikut:

$$
\text { Nilai Siswa }=\frac{\text { Skor mentah }}{\text { Skor maksimal }} \times 100
$$

menentukan rata-rata nilai siswa untuk setiap indikator kemampuan berpikir kritis dari nilai yang diperoleh siswa pada dua kali pertemuan, dari data tertulis.

$$
\bar{X}_{\text {Nilai Siswa }}=\frac{\text { Nilai pertemuan 1+Nilai pertemuan 2 }}{2}
$$

menentukan rata-rata nilai siswa untuk setiap indikator kemampuan berpikir kritis dari nilai yang diperoleh siswa pada dua kali pertemuan. dari data tes tertulis.

Tabel 1

Skala Kategori Kemampuan

\begin{tabular}{|c|c|}
\hline Nilai Siswa & $\begin{array}{c}\text { Tingkat Kemampuan } \\
\text { Berpikir Kritis }\end{array}$ \\
\hline $85-100$ & Sangat Baik \\
\hline $75-84$ & Baik \\
\hline $60-74$ & Cukup \\
\hline $40-59$ & Kurang \\
\hline $0-30$ & Sangat Kurang \\
\hline
\end{tabular}


Menghitung presentase sebaran siswa untuk masingmasing kategori kemampuan pada setiap kemampuan berpikir kritis menggunakan rumus :

$$
\text { Sebaran Siswa }(\%)=\frac{\sum X}{\Sigma Y} \times 100 \%
$$

Keterangan : persentase pada setiap indikator kemampuan berpikir kritis yaitu interpretasi, analisis, evaluasi, inferensi, kemampuan menjelaskan, dan self regulation siswa SMK Negeri 20 Samarinda kelas X Multimedia (MM). Hasil penelitian disajikan dalam bentuk gambar dan tabel persentase siswa secara keseluruhan pada setiap indikator kemampuan berpikir kritis, yang disajikan sebagai berikut :

\begin{tabular}{|c|c|c|c|c|c|c|c|c|c|c|c|}
\hline \multicolumn{12}{|c|}{$\begin{array}{c}\text { Tabel } 4 \\
\text { Data Sebaran Siswa }\end{array}$} \\
\hline \multirow{3}{*}{ No } & \multirow{3}{*}{ Indikator } & \multicolumn{10}{|c|}{ Kategori } \\
\hline & & \multicolumn{2}{|r|}{ SB } & \multicolumn{2}{|r|}{$\mathrm{B}$} & \multicolumn{2}{|r|}{$\mathrm{C}$} & \multicolumn{2}{|r|}{$\mathrm{K}$} & \multicolumn{2}{|r|}{ SK } \\
\hline & & $\%$ & Tafsiran & $\%$ & Tafsiran & $\%$ & Tafsiran & $\%$ & Tafsiran & $\%$ & Tafsiran \\
\hline 1 & Interpretasi & 10 & $\begin{array}{c}\text { Sebagian } \\
\text { kecil }\end{array}$ & 33,33 & $\begin{array}{c}\text { Hampir } \\
\text { separuhnya }\end{array}$ & 50 & Separuhnya & 6,67 & $\begin{array}{c}\text { Sebagian } \\
\text { kecil }\end{array}$ & 0 & Tidak ada \\
\hline 2 & $\begin{array}{l}\text { Kemampuan } \\
\text { menjelaskan }\end{array}$ & 6,67 & $\begin{array}{c}\text { Sebagian } \\
\text { kecil }\end{array}$ & 16,67 & $\begin{array}{c}\text { Sebagian } \\
\text { kecil }\end{array}$ & 40 & $\begin{array}{c}\text { Hampir } \\
\text { separuhnya }\end{array}$ & 33,33 & $\begin{array}{c}\text { Hampir } \\
\text { separuhnya }\end{array}$ & 3,33 & Sebagian kecil \\
\hline 3 & Inferensi & 6,67 & $\begin{array}{c}\text { Sebagian } \\
\text { kecil }\end{array}$ & 53,33 & $\begin{array}{c}\text { Sebagian } \\
\text { besar }\end{array}$ & 23,33 & $\begin{array}{c}\text { Sebagian } \\
\text { kecil }\end{array}$ & 16,67 & $\begin{array}{c}\text { Sebagian } \\
\text { kecil }\end{array}$ & 0 & Tidak ada \\
\hline 4 & Analisis & 30 & $\begin{array}{c}\text { Hampir } \\
\text { separuhnya }\end{array}$ & 70 & $\begin{array}{c}\text { Sebagian } \\
\text { besar }\end{array}$ & 0 & Tidak ada & 0 & Tidak ada & 0 & Tidak ada \\
\hline 5 & Evaluasi & 60 & Sebagian besar & 23,33 & $\begin{array}{c}\text { Sebagian } \\
\text { kecil }\end{array}$ & 10 & $\begin{array}{c}\text { Sebagian } \\
\text { kecil }\end{array}$ & 6,67 & $\begin{array}{c}\text { Sebagian } \\
\text { kecil }\end{array}$ & 0 & Tidak ada \\
\hline 6 & $\begin{array}{c}\text { Self } \\
\text { regulation }\end{array}$ & 0 & Tidak ada & 36,67 & $\begin{array}{c}\text { Hampir } \\
\text { separuhnya }\end{array}$ & 23,33 & $\begin{array}{c}\text { Sebagian } \\
\text { kecil }\end{array}$ & 40 & $\begin{array}{c}\text { Hampir } \\
\text { separuhnya }\end{array}$ & 0 & Tidak ada \\
\hline
\end{tabular}

$\sum \mathrm{X}=$ jumlah siswa pada kategori kemampuan

$\sum \mathrm{Y}=$ jumlah total siswa

Menafsirkan data sebaran yang diperoleh menggunakan kriteria yang dikemukakan oleh Koentjaraningrat seperti dalam tabel 2 berikut.

Tabel 2

Tafsiran Presentase Sebaran Siswa

\begin{tabular}{|c|c|}
\hline Presentase (\%) & Tafsiran Kualitatif \\
\hline 0 & Tidak ada \\
\hline $0-25$ & Sebagian kecil \\
\hline $26-49$ & Hampir Separuhnya \\
\hline 50 & Separuhnya \\
\hline $51-75$ & Sebagian Besar \\
\hline $76-99$ & Hampir Seluruhnya \\
\hline 100 & Seluruhnya \\
\hline
\end{tabular}

\section{HASIL DAN PEMBAHASAN}

Hasil analisis data yang diperoleh dari penelitian yang telah dilakukan berupa nilai
Keterangan :

SB : Sangat Baik

B : Baik

C : Cukup

K : Kurang

SK : Sangat Kurang

Penelitian ini bertujuan untuk mengetahui kemampuan berfikir kritis siswa yang terdiri dari kemampuan interpretasi, kemampuan menjelaskan, kemampuan inferensi, kemampuan analisis, kemampuan evaluasi dan kemampuan self regulation di kelas $\mathrm{X}$ Multimedia (MM) SMK Negeri 20 Samarinda yang berjumlah 30 orang siswa melalui model pembelajaran advance organizer.

Berdasarkan rata-rata nilai akhir pada kemampuan berpikir kritis siswa pada materi larutan elektrolit dan nonelektrolit untuk setiap indikator dapat dibuat gambar 1 sebagai berikut: 


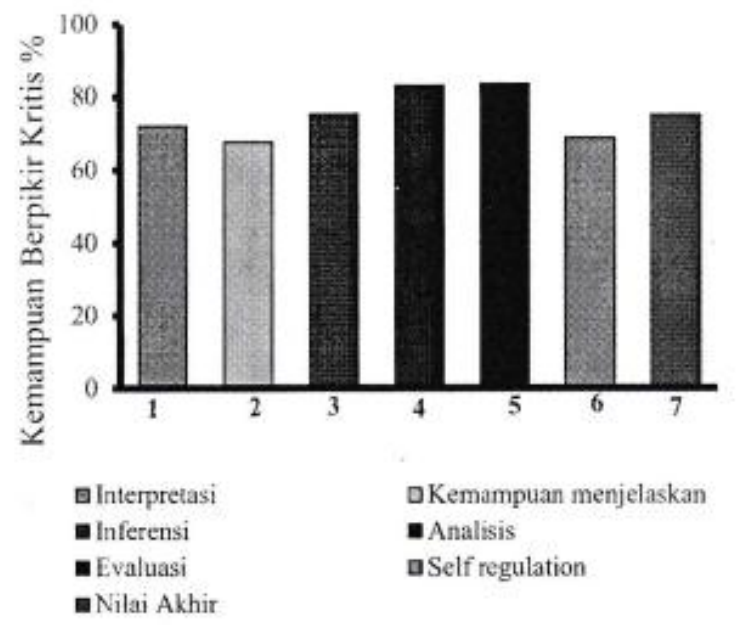

\section{Gambar 1 Rata-rata Nilai Tiap Indikator Kemampuan Berpikir Kritis Siswa untuk Seluruh Pertemuan}

Data yang ada menunjukkan bahwa siswa memiliki kemampuan yang paling baik dalam hal melakukan evaluasi atas benar atau tidaknya suatu informasi namun memiliki kemampuan menjelaskan dan self regulation atau pengaturan diri masuk dalam kategori cukup. Hal ini menunjukkan bahwa siswa lebih mampu untuk memilah informasi yang mereka terima dibanding mengatur diri mengenai apa yang harus mereka lakukan dalam menghadapi suatu permasalahan.

Kemampuan berpikir kritis siswa dapat dilihat dengan mengukur nilai keenam indikator di atas. Berdasarkan grafik di atas dapat dilihat bahwa indikator keterampilan berpikir kritis siswa yang memiliki nilai rata-rata tertinggi adalah evaluasi yaitu sebesar $83,67 \%$ yang termasuk dalam kategori baik. Hal ini tingkat kesulitan soal belum terlalu tinggi dikarenakan siswa sudah memiliki kemampuan untuk mengidentifikasi hubungan dari beberapa pernyataan, pertanyaan, konsep, deskripsi, dan berbagai model yang dipergunakan untuk merefleksikan pemikiran, pandangan, kepercayaan, keputusan, alasan, informasi dan opini. Mengevaluasi ide dan pendapat orang lain, mendeteksi argumen dan menganalisis argument.

Tingginya nilai siswa pada indikator evaluasi menunjukkan bahwa praktikum yang dilakukan sangat membantu siswa untuk memahami larutan elektrolit dan nonelektrolit melalui gejala daya hantar listrik larutan. Hal ini menyebabkan ketika siswa mendapatkan pertanyaan yang menunjukkan gejala daya hantar listrik larutan mampu untuk menggolongkan larutan yang ada kedalam larutan elektrolit dan non elektrolit.

Berdasarkan gambar 1 di atas dapat dilihat bahwa indikator keterampilan berpikir kritis siswa yang memiliki nilai rata-rata terendah adalah kemampuan menjelaskan yaitu sebesar 67,64\% dengan kategori cukup. Kemampuan menjelaskan memiliki tingkat kesulitan yang cenderung lebih tinggi dibandingkan tiga indikator sebelumnya yaitu interpretasi, eksplanation, dan inferensi, selain hal itu mengerjakan soal analisis ini perlu ketelitian, kemudian kemampuan untuk mengerti soal agar tidak salah persepsi, yang akan membuat hasil identifikasinya salah, diduga hal ini yang membuat nilai indikator kemampuan menjelaskan masuk dalam kategori cukup. Hal ini dikarenakan kemampuan siswa dalam menyatakan hasil pemikiran, menjelaskan alasan berdasarkan pertimbangan bukti, konsep metodologi. kriteriologi dan konteks masih belum maksimal. Termasuk dalam keterampilan ini adalah kemampuan menyampaikan hasil, menjelaskan prosedur. dan mempresentasikan argumen.

Indikator interpretasi memiliki soal yang hanya cenderung mengamati kemudian menjelaskan atau mendeskripsikan informasi yang diperoleh dari peristiwa, gejala, situasi, hingga dalam bentuk data. Grafik menunjukkan bahwa interpretasi sudah sangat cukup baik dimiliki oleh siswa sehingga dalam menghadapi soal itu bukan masalah yang sangat sulit bagi siswa. Kemampuan inferensi, evaluasi, dan self regulation mahasiswa masuk dalam kategori baik. Ketiga indikator merupakan indikator dengan tingkat kesulitan sedang hingga sangat sulit, meskipun begitu siswa masih memiliki kemampuan itu dengan baik, siswa memiliki kemampuan untuk memilih elemen penting dalam suatu soal yang nanti akan menjadi suatu jawaban dan simpulan, namun pada indikator kemampuan analisis siswa masuk dalam kategori cukup.

Secara keseluruhan untuk rata-rata nilai kemampuan berpikir kritis siswa kelas X Multimedia SMK Negeri 20 Samarinda tergolong baik dengan nilai diperoleh sebesar $75,08 \%$ yang menunjukkan bahwa sebagian besar siswa mampu berpikir kritis. Hal ini terjadi karena siswa mengerjakan soal LKS sesuai indikator berpikir kritis sebelum melakukan post test sehingga ketika diberi soal berpikir kritis siswa lebih mudah untuk mengerjakan. Membiasakan siswa mengerjakan soal 
yang sesuai indikator berpikir kritis akan membuat rata-rata siswa lebih baik.

Kendala pada penelitian dari keenam indikator ini adalah terbatasnya waktu guru untuk melakukan proses pembelajaran, siswa belum terbiasanya untuk melakukan proses pembelajaran bahkan belum pernah diberikan soal yang mengacu kepada keterampilan kritis yang cenderung lebih rumit, sehingga siswa sulit memahami maksud dari soal yang diberikan dan akhirnya siswa mengerjakan jawaban soal yang kurang lengkap dan kurang memenuhi ketepatan jawaban yang sesuai yang diminta. Selain itu siswa selalu dibiasakan menjadi pendengar yang baik dan guru yang berperan aktif dalam memberikan penjelasan di depan kelas sedangkan pada pembelajaran advance organizer, guru memberikan kesempatan kepada siswa untuk mengemukakan pendapat terhadap pelajaran yang dipelajari sehingga siswa merasa dihargai dan dapat menimbulkan motivasi ingin tahu, yang nantinya dapat menimbulkan rasa bangga dan percaya pada diri mereka. Siswa harus dibiasakan untuk melatih kemampuan berpikir kritis dengan memberikan pertanyaan ataupun masalah-masalah dalam ilmu kimia yang dapat mewakili indikator berpikir kitis. Hal ini dikarenakan bagi siswa latihan dan kebiasaan adalah hal yang sangat baik untuk melatih kemampuan otak sehingga kemampuan berpikir kritis siswa juga akan lebih baik, adapun secara keseluruhan keterampilan berpikir kritis siswa kelas X Multimedia SMK Negeri 20 Samarinda dapat dikatakan baik.

\section{PENUTUP}

\section{Kesimpulan}

Berdasarkan hasil penelitian dan analisis data dapat disimpulkan kemampuan berpikir kritis siswa kelas X Multimedia SMKN 20 Samarinda pada sub pokok bahasan larutan elektrolit dan nonelektrolit dengan model pembelajaran Advance Organizer sebesar 75,08\% dengan kategori baik.

\section{Saran}

Peneliti selanjutnya dapat mengembangkan model pembelajaran Advance Organizer ini pada mata pelajaran lain guna meningkatkan prestasi belajar siswa terutama pada kemampuan berfikir kritis siswa yang masih kurang.

\section{UCAPAN TERIMAKASIH}

Terimakasih penulis sampaikan kepada Ibu Triana Nur, S.Pd, selaku guru mata pelajaran kimia di SMK Negeri 20 Samarinda. Terimakasih penulis sampaikan kepada siswa-siswa SMK Negeri 20 Samarinda Kelas $\mathrm{X}$ Multimedia yang telah memberikan bantuan dan kerja samanya dalam menyelesaikan penelitian ini.

\section{DAFTAR PUSTAKA}

Arikunto. 2009. Dasar-dasar Evaluasi Pendidikan. Jakarta: Bumi Aksara

Facione, Peter A., 2004. Critical Thinking: What it is and Why it Count. Facione \& Gittens, Pearson Education.

http://academic.pgcc.edu/wpeirce/MCCCTR/Des igningrubricsassessingthinking.pdf. Diakses tanggal 23 Desember 2013.

Notoatmodjo, S. 2010, Metodologi Penelitian Kesehatan, Jakarta; Rineka Cipta.

Kusuma, W. 2011. Berpikir Kritis. http://www.scribd.com/doc/13065635/BerpikirKritis. (diakses tanggal 12 November 2013).

Trianto. 2007. Model-Model Pembelajaran Inovatif Berorientasi Konstruktivistik. Jakarta : Kencana Prenada Media Group.

Widiyowati I. 2015. Hubungan Kemampuan Berpikir Kritis dengan Respon Mahasiswa terhadap Penggunaan Model Pembelajaran Advance Organizer pada Materi Larutan Penyangga. Jurnal.unej.ac.id (Online) Tersedia: https://scholar.google.co.id/scholar (diakses Februari 2015).

Fachrurazi. 2011. Penerapan Pembelajaran Berbasis Masalah untuk Meningkatkan Kemampuan Berfikri Kritis dan Komunikasi Matematis Siswa Sekolah Dasar. Jurnal Pendidikan Edisi Khusus No. 1. Agustus 2011. (Online) Tersedia : http://jurnal.upi.edu/file/8Fachrurazi.pdf (diakses pada tanggal 8 November 2013). 